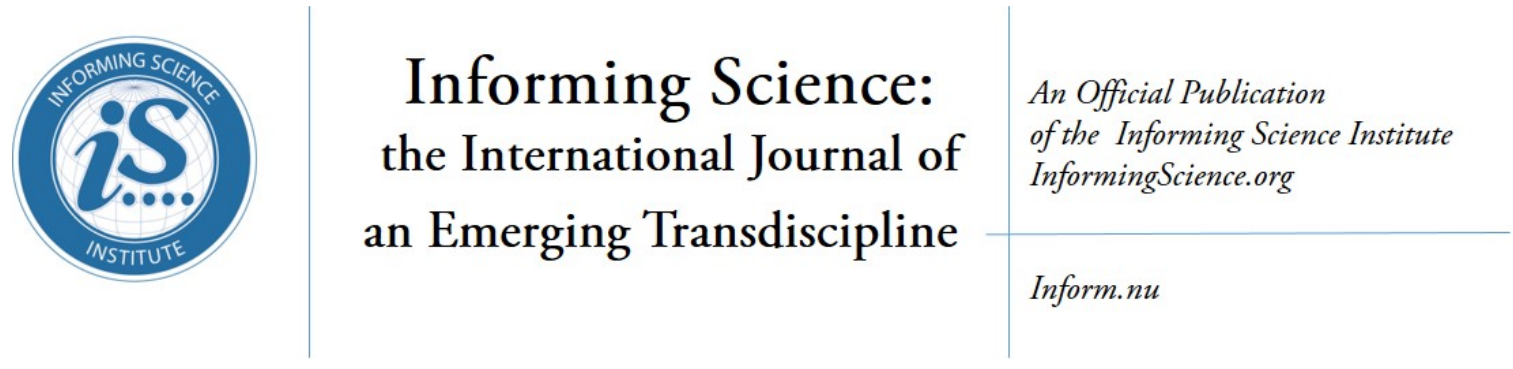

Volume 21, 2018

WHEN LESS IS MORE:

\title{
EMPIRICAL STUDY OF THE RELATION BETWEEN CONSUMER BEHAVIOR AND INFORMATION PROVISION ON COMMERCIAL LANDING PAGES
}

$\begin{array}{lll}\text { Nim Dvir* } & \begin{array}{l}\text { State University of New York at Albany, } \\ \text { Albany, NY, USA }\end{array} & \underline{\text { Ndvir@albany.edu }} \\ \text { Ruti Gafni } & \text { The Academic College of Tel Aviv Yaffo, } & \text { rutigafn@mta.ac.il } \\ & \text { Tel Aviv, Israel }\end{array}$

\begin{abstract}
Aim/Purpose This paper describes an empirical examination of how users' willingness to disclose personal data is influenced by the amount of information provided on landing pages - standalone web pages created explicitly for marketing or advertising campaigns.
\end{abstract}

Background Provision of information is a central construct in the IS discipline. Content is a term commonly used to describe the information made available by a website or other electronic medium. A pertinent debate among scholars and practitioners relate to the behavioral impact of content volume: Specifically, does a greater amount of information elicit engagement and compliance, or the other way around?

Methodology A series of large-scale web experiments ( $n=535$ and $n=27,900)$ were conducted employing a between-subjects design and A/B testing. Two variants of landing pages, long and short, were created based on relevant behavioral theories. Both variants included an identical form to collect users' information, but different amounts of provided content. User traffic was generated using Google AdWords and randomized between the page using Unbounce.com. Relevant usage metrics, such as response rate (called "conversion rate"), location, and visit time were recorded.

\footnotetext{
Accepting Editor Eli Cohen | Received: December 2, 2018| Revised: April 9, 2018 | Accepted: April 10, 2018.

Cite as: Dvir, N. \& Gafni, R. (2018). When less is more: Empirical study of the relation between consumer behavior and information provision on commercial landing pages. Informing Science: the International Journal of an Emerging Transdiscipline, 21, 19-39. https://doi.org/10.28945/4015

This is an expanded version of a paper presented at the 2018 InSITE Conference.

(CC BY-NC 4.0) This article is licensed to you under a Creative Commons Attribution-NonCommercial 4.0 International License. When you copy and redistribute this paper in full or in part, you need to provide proper attribution to it to ensure that others can later locate this work (and to ensure that others do not accuse you of plagiarism). You may (and we encourage you to) adapt, remix, transform, and build upon the material for any non-commercial purposes. This license does not permit you to use this material for commercial purposes.
} 
When Less is More

Contribution This research contributes to the body of knowledge on information provision and its effectiveness and carries practical and theoretical implications to practitioners and scholars in Information Systems, Informing Science, Communications, Digital Marketing, and related fields.

Findings Analyses of results show that the shorter landing pages had significantly higher conversion rates across all locations and times. Findings demonstrate a negative correlation between the content amount and consumer behavior, suggesting that users who had less information were more inclined to provide their data.

Recommendations At a practical level, results can empirically support business practices, design for Practitioners considerations, and content strategy by informing practitioners on the role of content in online commerce.

Recommendation Findings suggest that the amount of content plays a significant role in online for Researchers decision making and effective informing. They also contradict prior research on trust, persuasion, and security. This study advances research on the paradoxical relationship between the increased level of information and online decisionmaking and indicates that contrary to earlier work, not all persuasion theories are effective online.

Impact on Society Understanding how information drives behavior has implications in many domains (civic engagement, health, education, and more). This has relevance to system design and public communication in both online and offline contexts.

Future Research Using this research as a starting point, future research can examine the impact of content in other contexts, as well as other behavioral drivers (such as demographic data). This can lead to theoretical, methodological, and practical recommendations.

Keywords consumer behavior, information systems, content strategy, human computer interaction, informing science, user engagement, e-commerce, marketing, decision making

\section{INTRODUCTION AND BACKGROUND}

Provision of information is a central construct in the IS discipline (Delone \& McLean, 2003; Mishra, Stein, \& Burton-Jones, 2017). It is considered an important determinant of consumer behavior when using technology (Smith, 2017; Venkatesh, Thong, \& Xu, 2012). The complexity of informing users is of great interest in IS research, given that it is the linchpin through which systems have their effects (Burton-Jones \& Gallivan, 2007; Cohen, 1999; Mishra et al., 2017). This interest is also motivated by the growing proliferation and use of information and communications technologies (ICT) (Horrigan, 2017). For example, 93\% of adults in the U.S. report consuming information online, either via a mobile device or a computer (Smith, 2017). In the context of digital marketing and ecommerce, $79 \%$ of American adults reported ever making commercial transactions over computermediated networks (such as online purchases), spending nearly $\$ 350$ billion annually ("Carat Ad Spend Report," 2016; Smith \& Anderson, 2016).

A pertinent debate among scholars and practitioners relates to the amount of information: does more information elicit engagement and compliance, or the other way around? This paper empirically addresses this long-standing question by observing if the amount of provided information influences users' willingness to disclose personal data on a commercial landing page - a stand-alone web page created specifically for a marketing or advertising campaign (Becker, Broder, Gabrilovich, Josifovski, \& Pang, 2009; Unbounce, 2016). The action performed by the user is called "conversion" or "compliance". Since landing pages are typically users' first impression of a web page, decisions are greatly 
based on the content being presented (Ash, Page, \& Ginty, 2012; Becker et al., 2009; Lindgaard, Fernandes, Dudek, \& Brown, 2006; Reinecke et al., 2013).

In this study, information provision is operationalized by digital content amount. Digital content is defined as the textual or visual information made available by a website or other electronic medium (Gates, 1996; Huizingh, 2000; Rowley, 2008). In marketing and online commerce, digital content and digital information are often synonymous terms (Rowley, 2008).

The decision-making processes that make users comply online - disclose personal information or make a purchase - have been extensively researched in various domains. However, with regards to content, there is still a conceptual confusion resulting from competing models and theoretical underpinnings: on the one hand, research shows that more content eliminates uncertainty and reduces risk, therefore increasing trust (Cialdini, 2009; Fogg et al., 2002; Gefen, 2000; Lee \& Turban, 2001; Li \& Chatterjee, 2010; Luhmann, 2000). On the other hand, less content was suggested to reduce complexity and decrease effort, therefore increasing ease of use (Geissler, Zinkhan, \& Watson, 2006; Kahneman, 1973; Norton, Frost, \& Ariely, 2007; Song \& Schwarz, 2010; Vishwanath, 2004). As a result, the impact of the content amount is still an unsolved question.

This study uses the transdiscipline of Informing Science (Cohen, 2009) to address this research question. First, an extensive literature review was conducted to explore how best to inform clients using information technology and identify factors of effective information provision. Following, A between-group design and $\mathrm{A} / \mathrm{B}$ testing were utilized in a series of large-scale online experiments $(n=$ 535 and $n=27,083$ ). An A/B design is a two-part or phase design composed of a baseline ("A" phase) with no changes, and treatment or intervention ("B" phase). Two variants of landing pages, long and short, were created. Both variants had an identical form to collect users' information (e-mail address), but different amounts of provided content. User traffic to the pages was generated through online advertising, randomized between the variants and monitored to observe the difference in behavioral outcomes (conversions). If there is a change, then the treatment may be said to have had an effect (Kennedy, 2005).

The findings offer insights that carry practical and theoretical implications. At a practical level, results can inform practitioners on the role of content in online commerce and empirically support design considerations and content strategy. At the theoretical level, the research advances the body of knowledge on the correlation between information provision and IS effectiveness.

The rest of the paper is structured as follows: next, a literature review is presented to identify relevant research streams and formulate a research question. The following sections introduce the research design, describe the data collection, its analyses and discuss the research implications.

\section{LITERATURE REVIEW}

\section{THE INFORMING SCIENCE PHILOSOPHY}

The field of Informing Science explores what is the best way to inform users using information technology (Cohen, 1999, 2009). Informing science is a transdiscipline that supports the study of informing processes across a diverse set of academic disciplines. The transdisciplinary Informing Science framework and epistemology aim to reduce disciplinary bias, in particular regarding the complex phenomenon of providing consumers with information in a form, format, and schedule that maximizes its effectiveness (Cohen, 1999).

There are various dimensions of "information effectiveness", such as cognitive or psychological responses (Gill, 2015). However, a stable theme is that behavioral actions are still considered of central importance, and that IS use can be ultimately operationalized as behavior or activity (Burton-Jones \& Gallivan, 2007; Mishra et al., 2017). Previous research suggests that actual observable behavior outcome is a reliable measure, as other aspects, like perception and intention, are directly related to it 
(Figueiredo, Almeida, Benevenuto, \& Gummadi, 2014). In the current case, the observable behavioral outcome is disclosure of personal information, operationalized in the form of users providing their e-mail (conversion). This behavior is described as consumer's willingness to rely on the seller and take action in circumstances where such action makes the consumer vulnerable to the seller (Luhmann, 2017). It is often conceptualized as "compliance", defined as "behavior change devoid of pressure" (Cialdini \& Goldstein, 2002).

In the development of a robust framework, Informing Science drew from several well-known theories, such as Shannon and Weaver's Model of Communication process (Shannon, 1948), Wilson's model of information seeking behavior (1981) and Tversky \& Kahneman's framing theory (1985). The Informing Science Framework emphasizes the context of the client, the informer, and the transformation of a message between the two. The framework has three components: the informing environment, the delivery system, and the task-completion system (Cohen, 1999, 2009; Gill, 2015).

The process required to achieve effective informing is dependent on various aspects: the quality and rigor of the message on the part of the sender; potential value, relevance and usefulness with respect to the task being performed; and resonance, specifically addressing a message's impact on a client's mental models (Cohen, 2009; Gill, 2008).

Finally, effective informing can be defined and impacted by the levels of uncertainty and risk reduction as well as complexity and effort (Gill \& Cohen, 2008; Shannon, 1948; Wilson, 1981, 1997, 2000). Based on these observations, the following sections review the opposing streams of research on the relation between information provision and IS effectiveness.

\section{IN FAVOR OF MORE INFORMATION - REDUCING UNCERTAINTY AND RISK}

Literature that supports greater provision of information (amount of content) emphasizes that online commercial interactions involve a level of uncertainty and risk (Lee \& Turban, 2001; Lim, Sia, Lee, \& Benbasat, 2006; Luhmann, 2017). To mitigate it, web pages should display more content to generate trust, communicate value and signal quality (Eisingerich \& Bell, 2008; Gefen, 2000; Luhmann, 2017; Rainie \& Anderson, 2017).

Trust in an entity was argued to impact users' willingness to take action (Gefen, 2000; Luhmann, 2000, 2017). Trust in a website is based on its design and content (Mavlanova, Koufaris, BenbunanFich, \& Lang, 2015). In a commercial context, trusting beliefs occur when a consumer believes that the online store is benevolent, competent, honest, or predictable (Eisingerich \& Kretschmer, 2008; Jennings, 2000). Trust-building strategies include customer endorsements by similar (local, nonforeign) peers and privacy and security policy (Lim et al., 2006). Although consumers may not mind the collection and use of their data, they would like to know how the data will be used (Bélanger \& Crossler, 2011; Hargittai, Fullerton, Menchen-Trevino, \& Thomas, 2010; Jarvenpaa, Tractinsky, \& Saarinen, 2006). Online reviews and ratings were also found to be significant: most of the consumers consult online ratings and reviews when buying something for the first time (Gafni \& Golan, 2016; Smith \& Anderson, 2016).

Perceived value was also recognized as a factor of content. Research suggests that content is highly valued by online users and should convey information about the company, its products, and the level of service the consumer can expect to receive (Huizingh, 2000). The more useful information the website has, the more valuable it is for the users (Braun, Lee, Urban, \& Hauser, 2009; Coker, 2013; Wells, Valacich, \& Hess, 2011). Signals that form a perception of value are achieved by informative content, which includes the availability of customer reviews, shopping advice, articles, product information, and website policies (Gafni \& Golan, 2016; Li \& Chatterjee, 2010). Brynjolfsson and Smith (2000) found that good landing pages should explain the product or service offer and emphasize its value. 
Persuasion and influence. Content is also highlighted as a method for persuasion and influence. An established traditional theory is the Means-End Theory that suggests that to influence and persuade, the message should aim to lead the consumer to a desired end-state (Gutman, 1982). The six universal principles of social influence support to supplying information on authority, reciprocity, scarcity, social validation, likability and commitment and consistency (Cialdini, 2009; Cialdini \& Goldstein, 2002, 2004). Research on credibility has also highlighted the need for elaboration, for example, using online content to highpoint expertise or specify services (Fogg, 1998; Fogg et al., 2001, 2002; Laja, 2014; Tseng \& Fogg, 1999).

Quality. Signaling theory has been applied to digital content as a potential signal of product quality (Wells et al., 2011). Providing rich information represents an important signal, which in turn has a direct relationship with customers' purchase intention. Content signals may include product information, expert product reviews, press releases, frequently asked questions (FAQ), and news (Akdeniz, Calantone, \& Voorhees, 2013; Gao, Zhang, Wang, \& Ba, 2012). Rich content on a website is one of the most vital signals influencing perceptions of the overall quality of the website. At the same time, not providing an appropriate valuable content signals the seller's reluctance to invest time, effort, and resources in providing information (Gregg \& Walczak, 2008). The lack of detailed content may prompt buyers to believe that a seller has something to hide (Mavlanova et al., 2015).

"Perceived value", "Trust", "Persuasion and influence", and "Quality" are often used in support of long form, elaboration, or greater content volume. For example, Gefen (2000) and Eisingerich and Bell (2008) provided empirical evidence that greater volumes of information elicit familiarity and trust. Fogg et al. (2002) empirically demonstrated that elaboration and content volume are important factors when aiming to persuade and influence consumers online. Mavlanova et al. (2015) provided evidence that greater content volume signals quality and impacts perceived value. And Huizingh (2000) empirically demonstrated that, on average, larger websites seem to be 'richer' and more advanced.

Supporting arguments for more content are summarized in Table 1.

Table 1. Supporting arguments for more content

\begin{tabular}{|l|l|}
\hline DETERMINANT & \multicolumn{1}{c|}{ CONTENT FEATURES } \\
\hline Trust & $\begin{array}{l}\text { Trust in an entity affect people's willing- } \\
\text { ness to take action. } \\
\text { Content should include customer reviews, } \\
\text { shopping advice, product information and } \\
\text { the availability of website policies (e.g., } \\
\text { privacy policy). }\end{array}$
\end{tabular}

Perceived value Presence of relevant information provided on the website.

Convey intrinsic product attributes

Written product features, pictures, and virtual product experiences.

SUPPORTING RESEARCH (PARTIAL LIST)

Bélanger \& Crossler (2011);

Eisingerich \& Kretschmer (2008); Gafni \& Golan (2016); Gefen (2000); Hargittai et al. (2010); Jarvenpaa et al. (2006); Jennings (2000); Lim et al. (2006); Luhmann (2000, 2017); Smith \& Anderson (2016)

Braun et al. (2009); Brynjolfsson \& Smith (2000); Coker (2013); Gafni \& Golan (2016); Huizingh (2000); Li \& Chatterjee (2010);

Wells et al. (2011) 


\begin{tabular}{|l|l|l|}
\hline DETERMINANT & \multicolumn{1}{|c|}{ CONTENT FEATURES } & $\begin{array}{l}\text { SUPPORTING RESEARCH } \\
\text { (PARTIAL LIST) }\end{array}$ \\
$\begin{array}{ll}\text { Persuasion and } \\
\text { influence }\end{array}$ & $\begin{array}{l}\text { The message should aim to lead the con- } \\
\text { Sumer to the desired end-state. Content } \\
\text { should supply information on authority, (2009); Cialdini \& Gold- } \\
\text { reciprocity, scarcity, social validation (also } \\
\text { called social proof), likability, and com- } \\
\text { mitment and consistency. }\end{array}$ & $\begin{array}{l}\text { Fogg et al. (2001); Fogg et al. } \\
\text { (2002); Gutman (1982); Laja }\end{array}$ \\
& &
\end{tabular}

Quality Rich information signal quality, credibility, reputation and size.

Akdeniz et al. (2013); Gao et al. (2012); Gregg \& Walczak (2008); Mavlanova et al. (2015); Wells et al. (2011)

\section{IN FAVOR OF LESS INFORMATION - REDUCING COMPLEXITY AND EFFORT}

In contrast, some researchers argue against information provision because of the following reasons.

Effort. Some research suggested that effort is the real cost for users and that providing less information prevents complexity and enables ease-of-use (Nielsen, 2005; Nielsen \& Molich, 1990). Greater information provision signals effort while less information is easier to process (Norman, 2013). According to a study by Gofman, Moskowitz, and Mets (2009), $76 \%$ of consumers stated that the most important factor in a website's design is that it "makes it easy to find what I want."

Attention. The volume of content and the control of users' attention are inseparable. It takes users less than a second on average to evaluate a website's appeal after viewing it for the first time (Kolko, 2015). When the user's attention is diverted to access necessary information, there is an associated cost in time or effort, which is called the "Information access cost." It can come at a price: if processing the information is too demanding, the working memory disengages and moves on (Miller, 1956). Since much of the information available to users is increasingly abundant and immediately available, attention has become a limiting factor in the consumption of information (Davenport \& Beck, 2001). Prior research suggests that when faced with complex and uncertain situations, individuals tend to use simple heuristics and cues in a bounded rational decision-making process and make relatively 'uninformed' judgments based on a minimum of information (Brynjolfsson \& Smith, 2000). Research shows that elaboration (greater information provision) may result in "Friction," defined as a psychological resistance to a given element on the page (Lindgaard et al., 2006; Vishwanath, 2004).

Information overload. Research suggested that problems can arise when individuals with limited cognitive abilities encounter massive amounts of potentially relevant information (Y. C. Chen, Shang, \& Kao, 2009; Eppler \& Mengis, 2004). This phenomenon is called "Information overload" and is associated with a host of undesirable outcomes including poor decision-making and perception (Y. C. Chen et al., 2009; Lucian, 2014; Soto-Acosta, Jose Molina-Castillo, Lopez-Nicolas, \& ColomoPalacios, 2014). As a result, information interactions are becoming highly asymmetrical, with less than a third of the information provided online being noticed and read (Nielsen, 2015; Szabo \& Huberman, 2008).

Liking and curiosity. Finally, less content is scientifically shown to be easier to process but also leads to greater appreciation (Tuch, Presslaber, StöCklin, Opwis, \& Bargas-Avila, 2012). Research showed that more information leads, on average, to less liking and dissimilarity, while ambiguity breeds curiosity and interest (Norton et al., 2007). Information provision is suggested to alienate users by closing their "Knowledge Gap" (also called "Information Gap"), defined as the difference between what users know and what they would like to know (Losee, 2012; Menon \& Soman, 2002). 
Curiosity is generated when a person becomes aware that a knowledge gap exists - they would be motivated to search for more information to close the gap (Menon \& Soman, 2002).

Supporting arguments for less content are summarized in Table 2.

Table 2. Supporting arguments for less content

\begin{tabular}{|l|l|l|}
\hline DETERMINANT & \multicolumn{1}{|c|}{ CONTENT FEATURES } & \multicolumn{1}{c|}{$\begin{array}{c}\text { SUPORTING RESEARCH } \\
\text { (PARTIAL LIST) }\end{array}$} \\
\hline $\begin{array}{l}\text { Perceived effort } \\
\text { and ease of use }\end{array}$ & $\begin{array}{l}\text { Simple content is easier to process. } \\
\text { If processing the information is } \\
\text { too demanding, the } \\
\text { ing memory disengages and moves } \\
\text { on. }\end{array}$ & $\begin{array}{l}\text { Gofman et al. (2009); Nielsen (2005); } \\
\text { Nielsen \& Molich (1990); Norman } \\
(2013)\end{array}$ \\
\hline Attention & $\begin{array}{l}\text { When the user's attention is divert- } \\
\text { ed to access. } \\
\text { sary information, there is an asso- } \\
\text { ciated cost in time or effort. }\end{array}$ & $\begin{array}{l}\text { Brynjolfsson \& Smith (2000); Dav- } \\
\text { enport \& Beck (2001); Kolko (2015); } \\
\text { Lindgaard et al. (2006); Miller (1956); } \\
\text { Vishwanath (2004) }\end{array}$ \\
\hline $\begin{array}{l}\text { Information } \\
\text { overload }\end{array}$ & $\begin{array}{l}\text { Limited attention, poor decision } \\
\text { making, and negative perception }\end{array}$ & $\begin{array}{l}\text { Y. C. Chen et al. (2009); Eppler \& } \\
\text { Mengis (2004); Lucian (2014); Niel- } \\
\text { sen (2015); Soto-Acosta et al. (2014); } \\
\text { Szabo \& Huberman (2008) }\end{array}$ \\
\hline $\begin{array}{l}\text { Liking and } \\
\text { curiosity }\end{array}$ & $\begin{array}{l}\text { Curiosity is generated when } \\
\text { a person becomes aware that } \\
\text { a knowledge gap exists (less infor- } \\
\text { mation). }\end{array}$ & $\begin{array}{l}\text { Losee (2012); Menon \& Soman } \\
\text { (2002); Norton et al. (2007); Tuch et } \\
\text { al. (2012) }\end{array}$ \\
\hline \multicolumn{2}{|l}{} & \multicolumn{2}{|l}{} \\
\hline
\end{tabular}

\section{THE RESEARCH QUESTION}

The literature review has underlined a few gaps in current research:

(1) Lack of agreement and opposing theories on the advantages or disadvantages of elaboration on commercial web pages.

(2) No clear inference on how the volume of content influences consumer behavior.

(3) Most studies explore content features, yet not enough emphasis is on the volume of content.

(4) Research is limited, with few empirical studies on the effectiveness of landing pages. While there are many professional articles on the topic, there is a dearth of academic research that illuminates the role of content in landing pages, its influence on users' compliance or how it can be used for conversion optimization.

Therefore, the research questions that were formulated are the following: How does information provision influence consumer behavior? In the context of commercial landing pages, does providing more information correlate with increase or decrease in number of conversions?

The general hypothesis is that information provision impacts consumer behavior, and that changes to the amount of content impact system effectiveness. 


\section{RESEARCH METHODOLOGY}

To address these gaps, a between-subjects experimental design was adopted based on Informing Science's definition of a basic informing system, in which a single informer interacts directly with a clearly specified set of clients (Cohen, 2009; Gill, 2015).

\section{DESIGN}

The hypothesis was tested in a series of large-scale web experiments. All the experiments took place in commercial settings and focused exclusively on landing pages that appeared in response to clicking on online advertisements. The purpose of the landing pages is to persuade a visitor to act by completing a transaction: in this case, submission of an e-mail address (an action called "conversion").

A between-group experimental design was employed (Kennedy, 2005). All experiments were based on single-factorial A/B tests, also called "split testing." In an A/B test, two variations of the same page (" $\mathrm{A}$ " and " $\mathrm{B}$ ") are created and differ only in the element that is being tested (for this study purpose, the volume of content). Visitors were randomly assigned to the pages. External loading times, web addresses, and other external factors were equalized. Doing so enabled content to be isolated as an independent variable and thereby to observe its direct influence on a behavioral action as the outcome of interest. This method allowed establishing a causal relationship between changes and their influence on user-observable behavior with high probability.

\section{PAGE VARIANTS}

Two versions of landing pages were created: one with detailed information (control) and another version that seemed to be the same, only most of the information was removed (treatment), as presented in Figure 1. Both pages promoted a digital service - ClaimFame (www.claimfame.com ), a marketplace that connected content creators with talent on a broad range of media projects. Page variants included an identical form at the top of the page prompting the users to sign-up for a newsletter by providing their e-mail address. The page versions differed only in volume of content provided: variant $\mathrm{A}$ was based on theories of persuasion, trust, and signaling and included information on the service (perceived value), customer reviews (quality), and privacy policy (information on how

the personal data provided will be used, aimed to generate trust). Version B, on the contrary, had only the sign-up form and did not include any information on the service that consumers were signing up for or what will be done with their e-mail address. This variant emphasized the principles of simplicity, ease-of-use, and ambiguity.

Version "B" contained only 42 words, 211 characters, and 12 lines, with a simple call-to-action form; version " $A$ " was identical to version " $B$ ", but had additional information provided and, therefore, was longer and contained 278 words, 1,501 characters, and 49 lines.

The page variants were sent to an external consulting company and a panel of marketing experts to verify their internal and external validity. The experts corroborated the validity of the pages' design and confirmed that the variations in information provision adequately represent applied industry settings.

Figure 1 presents the two landing page variants: 


\section{VARIANT A: MORE CONTENT}

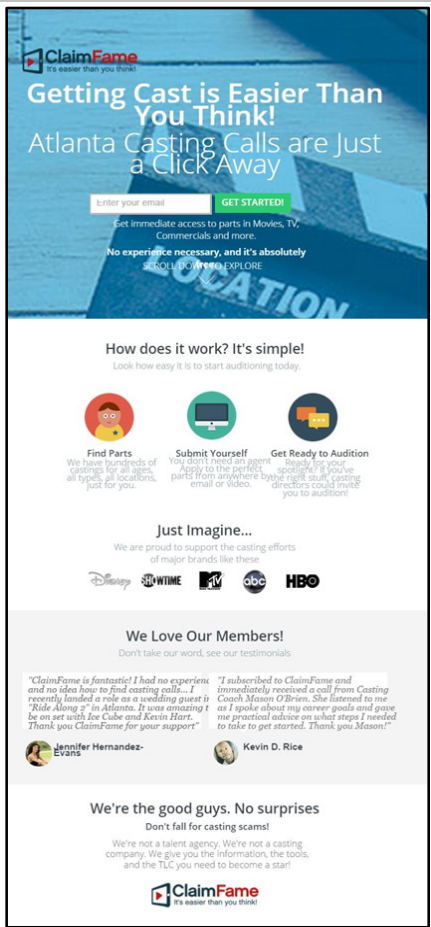

\section{VARIANT B: LESS CONTENT}

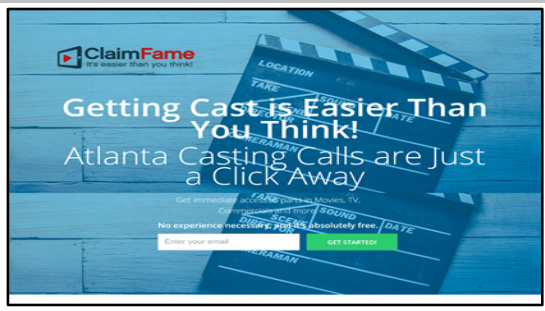

Figure 1. Page variations used for the experiments

\section{SAMPLE AND PARTICIPANTS}

Users' traffic to the pages was generated using Google AdWords, a commercial advertising tool that provides placement of paid advertisements in Google's search results based on relevant keywords (as shown in Figure 2). Google AdWords are increasingly used to recruit people into research studies. The service was proven to be a reliable method to recruit real-web users and to accurately control for location by targeting control areas (Jones, Goldsmith, Williams, \& Boulos, 2012).

\section{PROCEDURE AND DATA COLLECTION}

The pages were published online using Unbounce.com, a self-hosted service providing a suite of tools to create, publish, and test landing pages. Unbounce.com was chosen based on its popularity (It is widely used and regarded as a market trailblazer.) and its plethora of technical features and built-in web analytics, providing relatively simple means to create landing pages and quantitatively monitor their performance ("About Unbounce," 2015). Traffic was evenly split: 50\% of the users were shown page variant "A", while the other $50 \%$ were directed to variant "B". Unbounce.com uses cookies to make sure users were always directed to the same page and that the split would be equal. If users landed on page " $\mathrm{A}$ ", a cookie was placed on their computer so that even if they came back later, they would always see version "A". This was important to ensure that users would not notice the testing.

This type of experiment, called randomized controlled trial (RCT), is often used to ensure validity, reliability, and generalizability of web experiments: the randomization between different groups minimizes selection bias and the comparison of groups enables to observe any effects of the treatment when compared with the no treatment (control) group, while other variables are kept constant (Concato, Shah, \& Horwitz, 2000). 


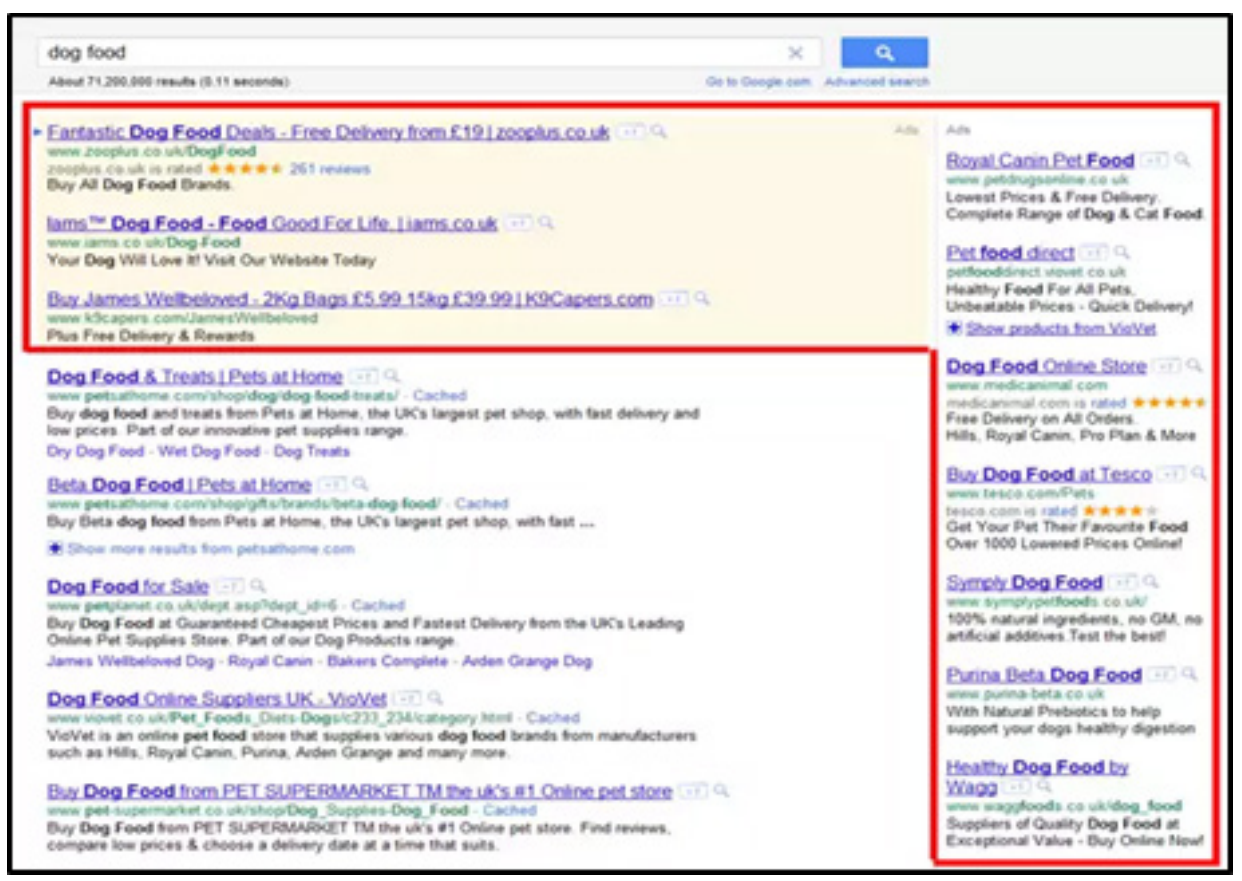

Figure 2. Example of Google AdWords used to recruit real web users.

Data was collected on all users that were directed to the pages, including click-through rates (total number of visits and number of unique visitors), users' IP address and locations, date and time of visits, and tracking of conversions (users who provided their e-mail addresses).

The results were analyzed using IBM SPSS version 22.

\section{Exploratory experiment}

An initial experiment was first set up to examine the viability of the design. Only users from a specific geographical location within the United States were targeted (Atlanta, Georgia). The experiment was set to stop when more than 200 conversions were reached (Google's guidelines recommend at least 100 conversions per page before deciding which version is best). Overall, the number of unique visitors directed to the page variations was $535(n=535)$.

\section{Extended experiments}

To better test the impact of information provision on consumer behavior, the exploratory experimentation was extended by conducting a broad nationwide, multi-market, split testing $(n=27,083)$. Five new experiments were performed in the same manner with different populations. The experiment used the same landing page variations from the exploratory experiment: version "A", with more information (long-form), and version "B", with less (short-form).

The sample size was expanded by directing a greater volume of user traffic using Google AdWords. This time geo-targeting was utilized to only include users in four specific regional US markets: Atlanta, Miami, Los Angeles, and New York. The experiments also maintained a fifth, "national" group that consisted of users located all over the United States. This well-known research method is called "Blocking" and is based on the arrangement of experimental units into groups consisting of units that are similar to one another (Addelman, 1969). Blocking reduces sources of variation between units and, thus, allows greater precision in the estimation of the source of variation under study (Concato et al., 2000).

In randomized block designs, there is one factor or variable that is of primary interest. However, there are also several other nuisance factors that may affect the measured result but are not of prima- 
ry interest. In this case, hour and day (time) is an example of such a factor. Within blocks, it is possible to assess the effect of different levels of the factor of interest without having to worry about variations due to changes of the block factors, which are accounted for in the analysis.

The expanded experiments were conducted over a two-month period. Overall, data was collected from 27,083 unique visits to the page variants.

\section{RESULTS}

The results of the exploratory experiment, as shown in Table 3, demonstrate a clear advantage in conversions on the short form pages.

Table 3- Summary of conversion results for exploratory experiment

\begin{tabular}{|l|l|l|l|l|}
\hline $\begin{array}{c}\text { PAGE VARI- } \\
\text { ANT }\end{array}$ & $\begin{array}{c}\text { TOTAL } \\
\text { UNIQUE } \\
\text { VISITORS }\end{array}$ & $\begin{array}{c}\text { CONVER- } \\
\text { SIONS }\end{array}$ & $\begin{array}{c}\text { USERS WHO } \\
\text { DIDN'T } \\
\text { CONVERT }\end{array}$ & $\begin{array}{c}\text { CONVER- } \\
\text { SION RATE }\end{array}$ \\
\hline "A" (Long) & 273 & 106 & 167 & $38.83 \%$ \\
\hline "B" (Short) & 262 & 140 & 122 & $53.44 \%$ \\
\hline Total & 535 & & & \\
\hline
\end{tabular}

As can be seen, the percentage of users who provided their e-mail was calculated as a percentage of the total amount of visitors to the page (conversion rate). Out of 535 visitors to both pages, on the long variant $38.83 \%$ of the users converted (provided their e-mail address). In comparison, in the short variant, the conversion was by $53.44 \%$ of the users. This is a significant $37.62 \%$ increase in conversion rate, rendering the short variant a clear winner. The results were statistically analyzed, showing significant difference between the groups ( $\mathrm{t}$-value -3.6569 , sig $0.00643, \mathrm{p}<0.05$ ), and chisquare $(11.4848, \mathrm{p}$-value is $0.000702, \mathrm{p}<0.05)$. These exploratory results motivate a more definite investigation.

In the extended experiments, data was collected from 27,083 unique visitors to the page variants. Their visits resulted in 9,593 conversions. See Table 4 for results:

Table 4. Summary of conversion results for expanded experiments

\begin{tabular}{|c|c|c|c|c|c|}
\hline $\begin{array}{l}\text { EXPERIMENT } \\
\text { / CAMPAIGN }\end{array}$ & $\begin{array}{c}\text { PAGE } \\
\text { VARIANT }\end{array}$ & $\begin{array}{c}\text { TOTAL } \\
\text { UNIQUE } \\
\text { VISITORS }\end{array}$ & CONVERSIONS & $\begin{array}{c}\text { CONVERSION } \\
\text { RATE }\end{array}$ & $\mathbf{t}$ \\
\hline \multirow{2}{*}{ National } & "A" (Long) & 5497 & 1405 & $26 \%$ & \multirow{2}{*}{$-6.651 * *$} \\
\hline & "B" (Short) & 5494 & 1718 & $31 \%$ & \\
\hline \multirow{2}{*}{ Atlanta } & "A" (Long) & 3690 & 1231 & $33 \%$ & \multirow{2}{*}{$\begin{array}{c}- \\
14.560 * *\end{array}$} \\
\hline & "B" (Short) & 3688 & 1838 & $50 \%$ & \\
\hline \multirow{2}{*}{ Miami } & "A" (Long) & 1235 & 444 & $36 \%$ & \multirow{2}{*}{$2.470^{* *}$} \\
\hline & "B" (Short) & 1237 & 639 & $52 \%$ & \\
\hline \multirow{2}{*}{ Los Angeles } & "A" (Long) & 1945 & 529 & $27 \%$ & \multirow{2}{*}{$\begin{array}{c}- \\
13.817^{* *}\end{array}$} \\
\hline & "B" (Short) & 1948 & 937 & $48 \%$ & \\
\hline \multirow{2}{*}{ New York } & "A" (Long) & 1176 & 324 & $28 \%$ & \multirow{2}{*}{$-8.946 * *$} \\
\hline & "B" (Short) & 1173 & 528 & $45 \%$ & \\
\hline \multirow{3}{*}{ Total } & “A” (Long) & 13543 & 3932 & $29 \%$ & \multirow{2}{*}{$\begin{array}{c}- \\
22.166^{* *} \\
\end{array}$} \\
\hline & "B" (Short) & 13540 & 5660 & $42 \%$ & \\
\hline & Both & 27,083 & 9,593 & & \\
\hline
\end{tabular}


As seen from Table 4 and in Figure 3, while a similar number of users were directed to the "A" or "B" variants in each market, the short variants significantly outperformed the long ones across all markets. T-tests were performed also for the percent of conversions in the " $\mathrm{A}$ " version groups for all the campaigns $(\mathrm{t}=-20.759, \mathrm{df}=119, \mathrm{sig}=.000)$ and for the percent of conversions in the " $\mathrm{B}$ " version groups for all campaigns $(\mathrm{t}=-20.131, \mathrm{df}=119$, $\mathrm{sig}=.000)$.

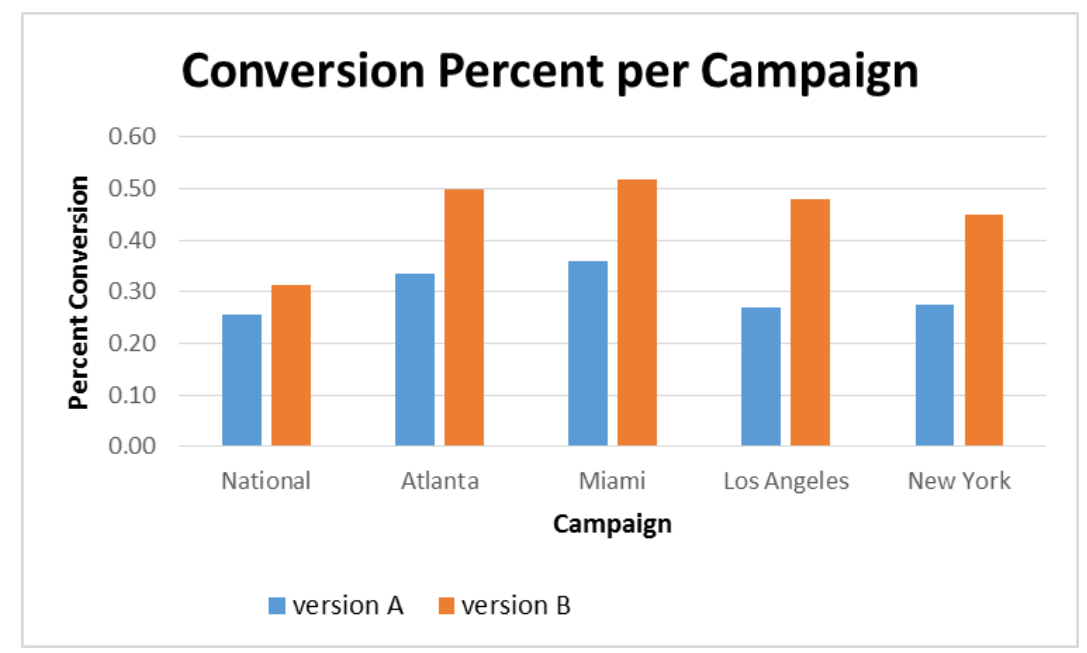

Figure 3. Comparison of "A" and "B" conversion percent for each campaign

\section{Location and time}

The results also suggest a possible influence of users' location on their conversion rate. As can be seen from Figure 3, there are differences between the various campaigns. In Miami, for example, people tend to convert more than other places, for both versions. In the National campaign, there were less conversions for both variants of the landing pages, in comparison to the targeted areas. In Los Angeles, the disparity between the conversion of the " $\mathrm{A}$ " and " $\mathrm{B}$ " versions is the greatest of all other markets.

While not significant, the fact that the percentage of conversions differed between locations must be further examined.

The influence of the time users visited the page was also checked. According to the time-stamp of each visit, the day of the week of each visit was computed (Sunday-Saturday). The day of the week may be an interesting parameter to study if leisure time affects the user's decision of conversion.

No differences were found between the day of the week and the average conversion of each page, for the sum of all experiments, as can be seen in Figure 4. T-test was performed between the average conversions for the " $\mathrm{A}$ " version for the different days in the week $(\mathrm{t}=10.805, \mathrm{df}=34, \mathrm{sig}=.000$, $\mathrm{p}<0.005)$, and same for the "B" version $(\mathrm{t}=10.341, \mathrm{df}=34$, sig=.000, $\mathrm{p}<0.005)$. No statistically significant correlations were found. The average conversions for both pages are similar during all days of the week, and the rate between the long page and the short one is similar in each day of the week. No statistical differences were found when checking each campaign. 
Dvir \& Gafni

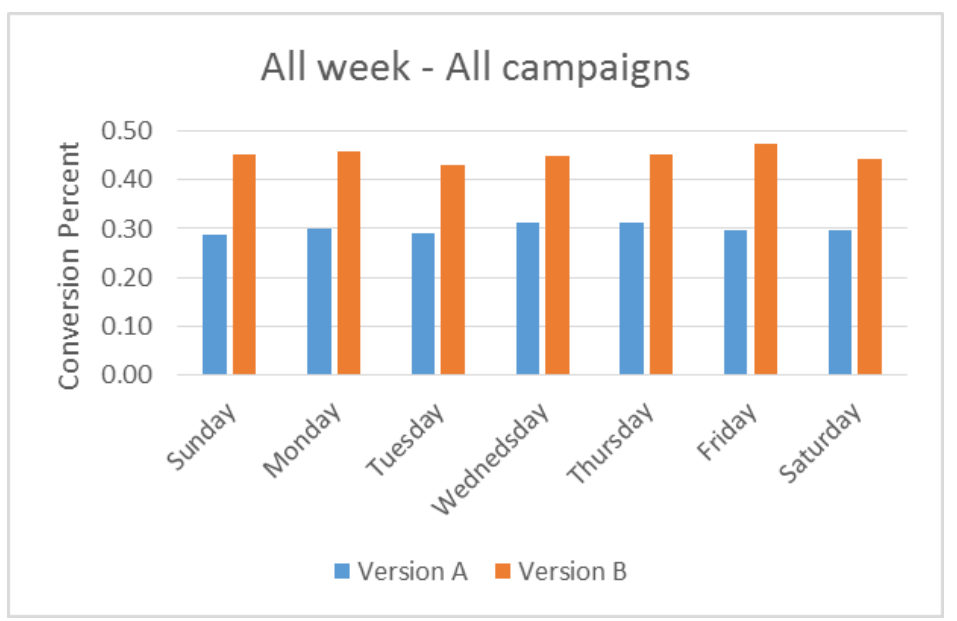

Figure 4. Conversion Percent for all campaigns together, all week long

Next, the hour of the visits was explored. Based the time-stamp, the hour of the day was extracted. The time-stamp was originated in New-York time zone. New York, Atlanta, and Miami correspond to the same time zone. To calculate the hour for Los Angeles visits, the time was reduced by 3 hours, thus, defining the "real" hour. The National campaign was omitted from this examination because the data was collected from all around the USA, with different time zones.

T-tests were performed to compare the "A" and "B" versions conversions for each hour. For all four campaigns together, for most of the hours, statistical differences were found between the campaigns.

Comparing each hour for the "A" version, between all four campaigns, there were no statistical differences in population behavior. The same result was observed for the "B" version.

The conversion rates between A and B versions across all 24 hours was examined. As can be seen in Figure 5 there were differences at the 5:00 and 22:00 times. These times can be associated with periods around waking up and going to bed.

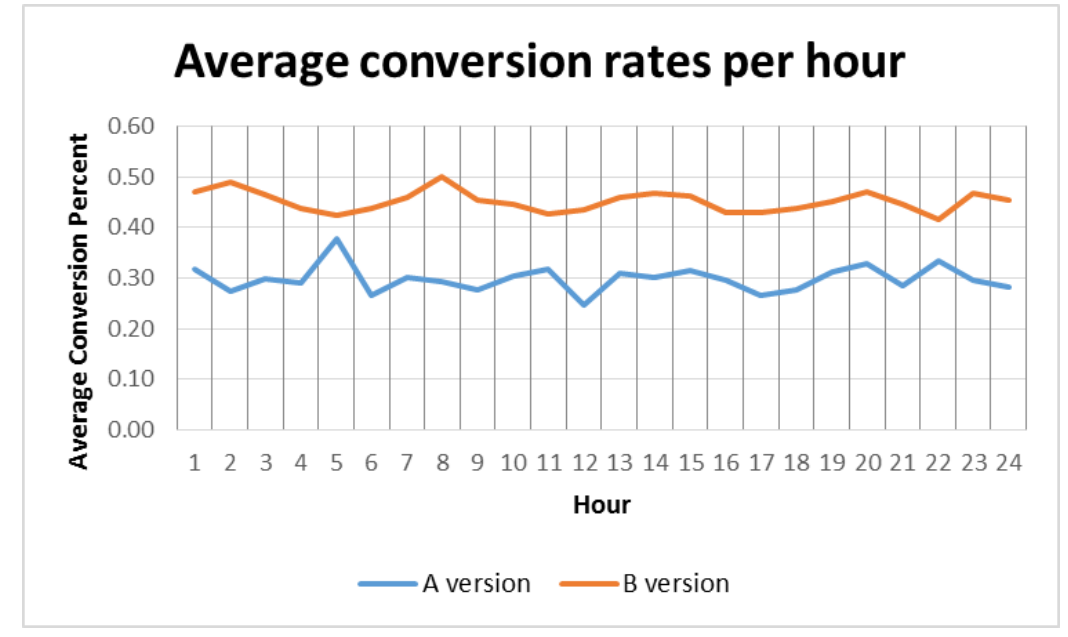

Figure 5. Average conversion rates for all campaigns together, per hour 


\section{DISCUSSION}

The findings across all the experiments demonstrate a negative correlation between the amount of information provided and users' conversions. The results show a significant advantage to the shorter pages. The short landing pages had higher conversion rates across all locations, days, and hours, and consistently outperformed their longer equivalents. Surprisingly, users who had less information were more inclined to provide their personal data.

These results have a few interesting implications.

\section{INFORMATION PROVISION IMPACTS CONSUMER BEHAVIOR}

First, an intuitive conclusion is that content is a crucial determinant of online consumer behavior. Since the research method allowed to control for intention and other variables, the amount of information provided was isolated as the only factor differentiating between the pages. The differences in the behavioral outcome shows that consumer behavior, especially conversions, hinges on the nature of the content being consumed. This supports prior research suggesting that digital content play a significant role in influencing online consumer behavior (Jarvenpaa et al., 2006; Jennings, 2000; Lee \& Turban, 2001; Wells et al., 2011).

\section{LESS INFORMATION PROVISION DRIVES DESIRED CONSUMER BEHAVIOR}

The results significantly show that provision of less information elicits better behavioral outcomes (conversions). In all the experiments, the landing pages with less content had significantly greater percentages of users willing to sign-up by providing their e-mail address (the desired outcome). This finding supports the research stream arguing for less content as a determinant of conversion.

\section{TRUST OR EASE-OF-USE?}

The results suggest an interesting insight on the determinants of online consumers behavior. As seen here, users that did not have any information on the service, its value, or how their data will be used still tended to convert more. By contrast, users who were provided with this information were less inclined to convert. This is in contradiction to previously discussed theories emphasizing the importance of trust, quality, and perceived value in online consumer behavior (Cialdini, 2009; Fogg, 2002; Lee \& Turban, 2001; Mishra et al., 2017).

The findings suggest that mitigating risks and conveying value are not always crucial determinants of consumers' willingness to act in circumstances where such act makes them vulnerable to the seller.

While previous studies show that more content promotes trust (Gefen, 2000; Lee \& Turban, 2001; Luhmann, 2000) and contributes to conversion (Cialdini, 2009; Fogg et al., 2002), this research shows otherwise. It supports prior work that suggests that increasing volume of content alienates users (Kahneman, 1973; Norton et al., 2007; Vishwanath, 2004).

\section{ONLINE DECISIONS ARE NOT ALWAYS PRAGMATIC}

The findings suggest that some online decisions, such as providing personal information on commercial web pages, are not always pragmatic. This behavior can even be described as irrational or paradoxical, as conventional wisdom suggests that commercial decisions are made under informed conditions. However, in the described experiments, the less users were informed the more they were willing to cooperate. It is, therefore, possible that individuals may make relatively 'uninformed' judgments based on a minimum of information, without engaging in any deep cognitive and conscious reflection. This supports the significance of "mental models" on online decision making (Gill, 2008; Gill \& Cohen, 2008). 


\section{THE IMPACT OF LOCATION AND TIME}

Results also showed some variations in observed behavior (conversion) in relation to users' location and time of visit. While not statistically significant, the fact that the percentage of conversions differed between locations and times indicate that content and information provision are not the only factors influencing behavior.

A possible hypothesis is that users' behavior differed in locations because of demographics (age, gender), economic status or personal preferences. The time of day can also be a factor influencing the rate of conversion. For example, while not significant, it was found that at 5:00 AM, when the people wake up, and at 10:00 PM, at the end of the day, consumers tend to convert in the long version ("A") more than in other times of the day. This may suggest that users have more attention span in the early morning and at night, while during the day they prefer less content. This is a question worth further investigation.

\section{CONCLUSION}

These results provide empirical evidence on the extent to which content by itself determines consumers' behavior. This research also contributes to the ongoing discussion on the type of information necessary to encourage website users and potential customers to take action.

The findings add some controversy to the relationship between the volume of content and consumers' behavior as they partially contradict other studies. They also contribute to the scholarly literature on landing pages and online behavior.

The conventional wisdom of the web suggests that more content elicits consumer knowledge and persuasion, which ultimately leads to more desirable behavioral goals. Previous studies suggested that web pages should display more content to generate trust, communicate value, and signal quality (C. W. Chen \& Koufaris, 2015; Eisingerich \& Kretschmer, 2008; Tversky \& Kahneman, 1985); Yet, this study found the opposite, as less content was shown to be a positive determinant of consumer behavior. While not enough to establish a linear relationship, results suggesting that "less is more" can go a long way in creating commercial value.

To the best of our knowledge, content volume and behavior on landing pages are rarely studied in isolation. This work falls within the broader vision of determining a method for effective communication on the web, which is of paramount importance in many theoretical and applied domains. Therefore, this research is unique and significant by focusing on the volume of content and landing pages, as the interplay between these factors is still highly debatable and under-explored.

This study makes a few theoretical and practical contributions. At the theoretical level, the findings provide evidence on the importance of informing consumers and the evolving importance of Informing Science. It provides progress in understanding how to maximize the effectiveness of the information provided to the client, which is integral to the definition of the Informing Science field (Cohen, 1999, 2009; Gill \& Cohen, 2008). It also points out areas of research that need further exploration and the need for refinement of the Informing Science framework. The empirical evidence suggests that contrary to previous work, not all behavioral and psychological theories are effective online. At a practical level, the results provide empirical support in favor of less content as a determinant of desired consumer behavior. The findings are informative for website designers, content strategists, and marketers and have implications for most businesses using the e-commerce or online marketing channels.

\section{LIMITATIONS AND FURTHER RESEARCH}

As in every behavioral study, a major limitation of this study is a difficulty to identify clear causation in human behavior. There are various factors that illicit cognitive and emotional responses of end- 
users; therefore, it is challenging to assess clear relationship due to the number of factors involved and possible competing hypotheses.

Also, the claim that "less is more" is grounded on the assumption of a linear relationship. However, one might suggest that this assumption might not be valid if the form is too short, making strong conclusions difficult.

Another limitation is that the results may not be generalized/applicable to other domains. The contested issue with regards to field experiments is their external validity. Given that field experiments necessarily take place in a specific geographic and political setting, the extent to which findings can be extrapolated to formulate a general theory regarding economic behavior is a concern.

It is important to remember that the findings presented here are limited and preliminary. There is a need to analyze additional data sets, as well as examine the influence of other variations in design elements and user demographics.

Using this research as a starting point, future research can examine the impact of content in other contexts. It is also interesting to explore other behavioral drivers beyond content, such as demographic data. It may be possible to do so in a two-stage design (a quantitative or qualitative study and then an experiment).

Finally, there is still no clear answer regarding which content features have the most influence on users, or what is the ideal volume of content. It will be valuable to explore other predictors, or identify specific content features that are more influential than others. Future work could also explore how to derive reliable and reusable metrics and methodologies that will inform the larger task of evaluating, developing and creating engaging content.

This study set the foundation for more exploration on how lack of knowledge paradoxically leads to higher conversions and overall user compliance. This research can argue in favor of the persuasive power of ambiguity and simplicity. The framework developed in this paper can serve as the basis for further studies on conversion and persuasion in online settings and other domains.

\section{REFERENCES}

About Unbounce: Create Better Marketing Experiences. (2015). Retrieved November 24, 2015, from http://unbounce.com/about/

Addelman, S. (1969). The generalized randomized block design. The American Statistician, 23(4), 35. https://doi.org/10.2307/2681737

Akdeniz, B., Calantone, R. J., \& Voorhees, C. M. (2013). Effectiveness of marketing cues on consumer perceptions of quality: The moderating roles of brand reputation and third-party information. Psychology \& Marketing, 30(1), 76-89. https://doi.org/10.1002/mar.20590

Ash, T., Page, R., \& Ginty, M. (2012). Landing page optimization: The definitive guide to testing and tuning for conversions (2nd ed). Indianapolis, IN: John Wiley \& Sons.

Becker, H., Broder, A., Gabrilovich, E., Josifovski, V., \& Pang, B. (2009). What happens after an ad click? Quantifying the impact of landing pages in web advertising. In Proceedings of the 18th ACM conference on Information and Knowledge Management (pp. 57-66). ACM. Retrieved from http:/ / dl.acm.org/citation.cfm?id=1645964

Bélanger, F. \& Crossler, R. E. (2011). Privacy in the digital age: A review of information privacy research in information systems. MIS Quarterly, 35(4), 1017-1041. https://doi.org/10.2307/41409971

Braun, M., Lee, C., Urban, G., \& Hauser, J. R. (2009). Does matching website characteristics to cognitive styles increase online sales? Retrieved from http://web.mit.edu/ hauser/www/Papers/Braun-Lee-UrbanHauser $\% 20$ Web $\% 20$ Style $\% 20$ Match $\% 2012-03-09$.pdf 
Brynjolfsson, E., \& Smith, M. D. (2000). Frictionless commerce? A comparison of Internet and conventional retailers. Management Science, 46(4), 563-585. https://doi.org/10.1287/mnsc.46.4.563.12061

Burton-Jones, A., \& Gallivan, M. J. (2007). Toward a Deeper Understanding of System Usage in Organizations: A Multilevel Perspective. MIS Quarterly, 31(4), 657-679. https://doi.org/10.2307/25148815

Carat Ad Spend Report. (2016). Retrieved December 15, 2015, from http://dentsuaegisnetwork.com/m/enUK/Carat $\% 20 \mathrm{Ad} \% 20$ Spend $\% 20$ Sept $\% 202015 /$ Carat $\% 20 \mathrm{Ad} \% 20$ Spend $\% 20$ Sept $^{2} \% 202015 \% 20$ FINAL.pdf

Chen, C. W., \& Koufaris, M. (2015). The impact of decision support system features on user overconfidence and risky behavior. European Journal of Information Systems, 24(6), 607-623. https://doi.org/10.1057/ejis.2014.30

Chen, Y. C., Shang, R. A., \& Kao, C. Y. (2009). The effects of information overload on consumers' subjective state towards buying decision in the internet shopping environment. Electronic Commerce Research and Applications, 8(1), 48-58. https://doi.org/10.1016/j.elerap.2008.09.001

Cialdini, R. B. (2009). Influence: Science and practice (Vol. 4). Pearson Education Boston. Retrieved from http://www.vulkani.rs/cached/www.vulkani.rs/Images/f30b6f14-40ec-49c3-b480-bbef1ea8c34e000003883.pdf

Cialdini, R. B., \& Goldstein, N. J. (2002). The science and practice of persuasion. The Cornell Hotel and Restaurant Administration Quarterly, 43(2), 40-50. https://doi.org/10.1016/S0010-8804(02)80030-1

Cialdini, R. B., \& Goldstein, N. J. (2004). Social influence: Compliance and conformity. Annual Review of Psychology, 55(1), 591-621. https://doi.org/10.1146/annurev.psych.55.090902.142015

Cohen, E. (1999). Reconceptualizing information systems as a field of the transdiscipline informing science: From ugly duckling to swan. Journal of Computing and Information Technology, 7(3), 213-219.

Cohen, E. (2009). A philosophy of informing science. Informing Science: The International Journal of an Emerging Transdiscipline, 12(1), 15. Retrieved from http://www.inform.nu/Articles/Vol12/ISJv12p001015Cohen399.pdf

Coker, B. (2013). Antecedents to website satisfaction, loyalty, and word-of-mouth. JISTEM-Journal of Information Systems and Technology Management, 10(2), 209-218. https://doi.org/10.4301/S1807-17752013000200001

Concato, J., Shah, N., \& Horwitz, R. I. (2000). Randomized, controlled trials, observational studies, and the hierarchy of research designs. New England Journal of Medicine, 342(25), 1887-1892. https://doi.org/10.1056/NEJM200006223422507

Davenport, T. H., \& Beck, J. C. (2001). The attention economy: understanding the new currency of business. Boston, Mass: Harvard Business School Press.

Delone, W. H., \& McLean, E. R. (2003). The DeLone and McLean model of information systems success: A ten-year update. Journal of Management Information Systems, 19(4), 9-30.

https://doi.org/10.1080/07421222.2003.11045748

Eisingerich, A. B., \& Bell, S. J. (2008). Customer education increases trust. MIT Sloan Management Review, (Fall 2008). Retrieved from http://sloanreview.mit.edu/article/customer-education-increases-trust/

Eisingerich, A. B., \& Kretschmer, T. (2008). In e-commerce, more is more. Harvard Business Review. Retrieved from https://hbr.org/2008/03/in-e-commerce-more-is-more

Eppler, M. J., \& Mengis, J. (2004). The concept of information overload: A review of literature from organization science, accounting, marketing, MIS, and related disciplines. The Information Society, 20(5), 325-344. https://doi.org/10.1080/01972240490507974

Figueiredo, F., Almeida, J. M., Benevenuto, F., \& Gummadi, K. P. (2014). Does content determine information popularity in social media? A case study of You'Tube videos' content and their popularity. In Proceedings of the SIGCHI Conference on Human Factors in Computing Systems (pp. 979-982). New York, NY, USA: ACM. https://doi.org/10.1145/2556288.2557285

Fogg, B. J. (1998). Charismatic computers: Creating more likable and persuasive interactive technologies by leveraging principles from social psychology. Stanford University, Stanford, CA, USA. 
Fogg, B. J., Marshall, J., Kameda, T., Solomon, J., Rangnekar, A., Boyd, J., \& Brown, B. (2001). Web credibility research: A method for online experiments and early study results. In CHI '01 Extended Abstracts on Human Factors in Computing Systems (pp. 295-296). New York, NY, USA: ACM. https://doi.org/10.1145/634067.634242

Fogg, B. J., Soohoo, C., Danielson, D., Marable, L., Stanford, J., \& Tauber, E. R. (2002). How do people evaluate a web site's credibility (Research report). Persuasive Technology Lab: Stanford University. Retrieved from http://citeseerx.ist.psu.edu/viewdoc/summary?doi=10.1.1.125.8137

Gafni, R., \& Golan, O. T. (2016). The influence of negative consumer reviews in social networks. Online Journal of Applied Knowledge Management, 4(2), 44-58.

Gao, J., Zhang, C., Wang, K., \& Ba, S. (2012). Understanding online purchase decision making: The effects of unconscious thought, information quality, and information quantity. Decision Support Systems, 53(4), 772781. https://doi.org/10.1016/i.dss.2012.05.011

Gates, B. (1996, January 3). Content is king. Retrieved October 29, 2017, from http://web.archive.org/web/20010126005200/http://www.microsoft.com/billgates/columns/1996essav/ essay960103.asp

Gefen, D. (2000). E-commerce: The role of familiarity and trust. Omega, 28(6), 725-737. https://doi.org/10.1016/S0305-0483(00)00021-9

Geissler, G. L., Zinkhan, G. M., \& Watson, R. T. (2006). The influence of home page complexity on consumer attention, attitudes, and purchase intent. Journal of Advertising, 35(2), 69-80. https://doi.org/10.1080/00913367.2006.10639232

Gill, G. (2008). The single client resonance model: Beyond rigor and relevance. Informing Science: The International Journal of an Emerging Transdiscipline, 11, 281-310. https://doi.org/10.28945/449

Gill, G. (2015). Informing science volume one: Concepts and systems. Santa Rosa, CA, USA: Informing Science Press.

Gill, G., \& Cohen, E. (2008). Research themes in complex informing. Informing Science: The International Journal of an Emerging Transdiscipline, 11, 147-164.

Gofman, A., Moskowitz, H. R., \& Mets, T. (2009). Integrating science into web design: consumer-driven web site optimization. Journal of Consumer Marketing, 26(4), 286-298. https://doi.org/10.1108/07363760910965882

Gregg, D. G., \& Walczak, S. (2008). Dressing your online auction business for success: An experiment comparing two eBay businesses. MIS Quarterly, 32(3), 653-670. https://doi.org/10.2307/25148860

Gutman, J. (1982). A means-end chain model based on consumer categorization processes. Journal of Marketing, 46(2), 60-72. https://doi.org/10.2307/3203341

Hargittai, E., Fullerton, L., Menchen-Trevino, E., \& Thomas, K. Y. (2010). Trust online: Young adults' evaluation of web content. International Journal of Communication, 4, 468-494. Retrieved from http://ijoc.org/index.php/ijoc/article/view/636

Horrigan, J. B. (2017, September 11). How people approach facts and information. Retrieved January 19, 2018, from http://www.pewinternet.org/2017/09/11/how-people-approach-facts-and-information/

Huizingh, E. K. R. E. (2000). The content and design of web sites: An empirical study. Information \& Management, 37(3), 123-134. https://doi.org/10.1016/S0378-7206(99)00044-0

Jarvenpaa, S. L., Tractinsky, N., \& Saarinen, L. (2006). Consumer trust in an internet store: A cross-cultural validation. Journal of Computer-Mediated Communication, 5(2). https://doi.org/10.1111/j.10836101.1999.tb00337.x

Jennings, M. (2000). Theory and models for creating engaging and immersive ecommerce websites. In Proceedings of the 2000 ACM SIGCPR conference on Computer Personnel Research (pp. 77-85). ACM. https://doi.org/10.1145/3333334.333358 
Jones, R. B., Goldsmith, L., Williams, C. J., \& Kamel Boulos, M. N. (2012). Accuracy of geographically targeted internet advertisements on Google AdWords for recruitment in a randomized trial. Journal of Medical Internet Research, 14(3), e84. https://doi.org/10.2196/jmir.1991

Kahneman, D. (1973). Attention and effort. Citeseer. Retrieved from http://citeseerx.ist.psu.edu/viewdoc/download?doi=10.1.1.398.5285\&rep=rep1\&type=pdf

Kennedy, C. H. (2005). Single-case designs for educational research. Boston: Pearson

Kolko, J. (2015, September 1). Design thinking comes of age. Harvard Business Review. Retrieved from https://hbr.org/2015/09/design-thinking-comes-of-age

Laja, P. (2014, May 7). What's the point of landing pages? Why not drive traffic to your home page? Retrieved December 16, 2015, from http://blog.getresponse.com/traffic-with-landing-pages.html

Lee, M. K. O., \& Turban, E. (2001). A trust model for consumer internet shopping. International Journal of Electronic Commerce, 6(1), 75-91. https://doi.org/10.1080/10864415.2001.11044227

Li, H., \& Chatterjee, S. (2010). Designing effective persuasive systems utilizing the power of entanglement: Communication channel, strategy and affect. Persuasive Technology, 274-285. https://doi.org/10.1007/978$\underline{3-642-13226-1 \quad 27}$

Lim, K. H., Sia, C. L., Lee, M. K. O., \& Benbasat, I. (2006). Do I trust you online, and if so, will I buy? An empirical study of two trust-building strategies. Journal of Management Information Systems, 23(2), 233-266. https://doi.org/10.2753/MIS0742-1222230210

Lindgaard, G., Fernandes, G., Dudek, C., \& Brown, J. (2006). Attention web designers: You have 50 milliseconds to make a good first impression! Behaviour \& Information Technology, 25(2), 115-126. https://doi.org/10.1080/01449290500330448

Losee, R. M. (2012). Information from processes. Berlin, Heidelberg: Springer Berlin Heidelberg. https://doi.org/10.1007/978-3-642-31190-1

Lucian, R. (2014). Digital overload: The effects of the large amounts of information when purchasing online. Journal of Internet Banking and Commerce, 19(2). Retrieved from http://www.icommercecentral.com/openaccess/digital-overload-the-effects-of-the-large-amounts-of-information-when-purchasingonline.php?aid $=37973$

Luhmann, N. (2000). Familiarity, confidence, trust: Problems and alternatives. Trust: Making and Breaking Cooperative Relations, 6, 94-107.

Luhmann, N. (2017). Trust and power. John Wiley \& Sons.

Mavlanova, T., Koufaris, M., Benbunan-Fich, R., \& Lang, G. (2015). The effect of positive and negative signals on perceived deceptiveness of websites in online markets. Journal of Theoretical and Applied Electronic Commerce Research, 10(1), 19-34. https://doi.org/10.4067/S0718-18762015000100003

Menon, S., \& Soman, D. (2002). Managing the power of curiosity for effective web advertising strategies. Journal of Advertising, 31(3), 1-14. https://doi.org/10.1080/00913367.2002.10673672

Miller, G. A. (1956). The magical number seven, plus or minus two: Some limits on our capacity for processing information. Psychological Review, 101(2), 343-352. https://doi.org/10.1037/0033-295X.101.2.343

Mishra, A., Stein, M.-K., \& Burton-Jones, A. (2017). IS use. MIS Quarterly Research Curations. Retrieved from https://www.misqresearchcurations.org/blog/2017/12/1/is-use

Molich, R., \& Nielsen, J. (1990). Improving a human-computer dialogue. Communications of the ACM, 33(3), 338-348. https://doi.org/10.1145/77481.77486

Nielsen, J. (2005). Ten usability heuristics. Retrieved December 19, 2013 from http://www.nngroup.com/articles/ten-usability-heuristics/

Nielsen, J. (2015, November 15). Legibility, readability, and comprehension: Making users read your words. Retrieved October 26, 2017, from https://www.nngroup.com/articles/legibility-readability-comprehension/ 
Nielsen, J., \& Molich, R. (1990). Heuristic evaluation of user interfaces. In Proceedings of the SIGCHI conference on Human factors in computing systems (pp. 249-256). ACM. https://doi.org/10.1145/97243.97281

Norman, D. A. (2013). The design of everyday things (Revised and expanded edition). New York, New York: Basic Books.

Norton, M. I., Frost, J. H., \& Ariely, D. (2007). Less is more: The lure of ambiguity, or why familiarity breeds contempt. Journal of Personality and Social Psychology, 92(1), 97-105. https://doi.org/10.1037/0022$\underline{3514.92 .1 .97}$

Rainie, L., \& Anderson, J. (2017, August 10). The fate of online trust in the next decade. Retrieved November 17, 2017, from http://www.pewinternet.org/2017/08/10/the-fate-of-online-trust-in-the-next-decade/

Reinecke, K., Yeh, T., Miratrix, L., Mardiko, R., Zhao, Y., Liu, J., \& Gajos, K. Z. (2013). Predicting users' first impressions of website aesthetics with a quantification of perceived visual complexity and colorfulness. In Proceedings of the SIGCHI Conference on Human Factors in Computing Systems (pp. 2049-2058). ACM. https://doi.org/10.1145/2470654.2481281

Rowley, J. (2008). Understanding digital content marketing. Journal of Marketing Management, 24(5-6), 517-540. https://doi.org/10.1362/026725708X325977

Shannon, C. E. (1948). A mathematical theory of communication. Bell System Technical Journal, 27(3), 379-423. https://doi.org/10.1002/j.1538-7305.1948.tb01338.x

Smith, A. (2017). Record shares of Americans now own smartphones, have home broadband. Pew Research Center. Retrieved from http://www.pewresearch.org/fact-tank/2017/01/12/evolution-of-technology/

Smith, A., \& Anderson, M. (2016, December 19). Online shopping and e-commerce. Retrieved May 29, 2017, from http://www.pewinternet.org/2016/12/19/online-shopping-and-e-commerce/

Song, H., \& Schwarz, N. (2010). If it's easy to read, it’s easy to do, pretty, good, and true. Psychologist, 23(2), 108111. Retrieved from https://thepsychologist.bps.org.uk/volume-23/edition-2/if-its-easy-read-its-easy-dopretty-good-and-true

Soto-Acosta, P., Jose Molina-Castillo, F., Lopez-Nicolas, C., \& Colomo-Palacios, R. (2014). The effect of information overload and disorganisation on intention to purchase online: The role of perceived risk and internet experience. Online Information Review, 38(4), 543-561. https://doi.org/10.1108/OIR-01-2014-0008

Szabo, G., \& Huberman, B. A. (2008). Predicting the popularity of online content. ArXiv:0811.0405 [Physics]. https://doi.org/10.2139/ssrn.1295610

Tseng, S., \& Fogg, B. J. (1999). Credibility and computing technology. Communications of the ACM, 42(5), 39-44. https://doi.org/10.1145/301353.301402

Tuch, A. N., Presslaber, E. E., StöCklin, M., Opwis, K., \& Bargas-Avila, J. A. (2012). The role of visual complexity and prototypicality regarding first impression of websites: Working towards understanding aesthetic judgments. International Journal of Human-Computer Studies, 70(11), 794-811. https://doi.org/10.1016/i.ijhcs.2012.06.003

Tversky, A., \& Kahneman, D. (1985). The framing of decisions and the psychology of choice. In V. T. Covello, J. L. Mumpower, P. J. M. Stallen, \& V. R. R. Uppuluri (Eds.), Environmental impact assessment, Technology assessment, and risk analysis (pp. 107-129). Springer, Berlin, Heidelberg. https://doi.org/10.1007/978-3-642$\underline{70634-9 \quad 6}$

Unbounce. (2016). What is a Landing Page? Retrieved December 11, 2016, from https://unbounce.com/landingpage-articles/what-is-a-landing-page/

Venkatesh, V., Thong, J., \& Xu, X. (2012). Consumer acceptance and use of information technology: Extending the unified theory of acceptance and use of technology. MIS Quarterly, 36, 157-178.

Vishwanath, A. (2004). An empirical investigation into the use of heuristics and information cues by bidders in online auctions. Electronic Markets, 14(3), 178-185. https://doi.org/10.1080/1019678042000245100

Wells, J. D., Valacich, J. S., \& Hess, T. J. (2011). What signal are you sending? How website quality influences perceptions of product quality and purchase intentions. MIS Quarterly, 35, 373-396.

https://doi.org/10.2307/23044048 
Dvir \& Gafni

Wilson, T. D. (1981). On user studies and information needs. Journal of Documentation, 37(1), 3-15. https://doi.org/10.1108/eb026702

Wilson, T. D. (1997). Information behaviour: An interdisciplinary perspective. Information Processing \& Management, 33(4), 551-572. https://doi.org/10.1016/S0306-4573(97)00028-9

Wilson, T. D. (2000). Human information behavior. Informing Science: The International Journal of an Emerging Transdiscipline, 3(2), 49-56. https://doi.org/10.28945/576

\section{BIOGRAPHIES}

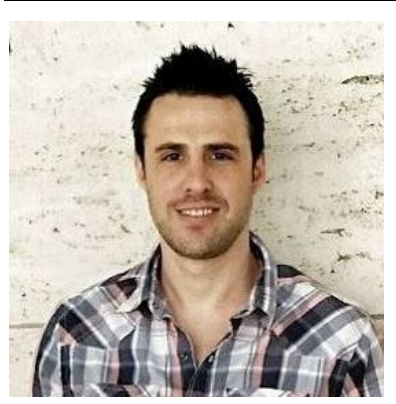

Nim Dvir is a Ph.D. student in the Information Studies department at the University at Albany. His main research interests are human-computer interaction (HCI), user experience (UX), E-Commerce, Content Strategy, and online user behavior. His work explores the determinants of perception, motivation, engagement, and decision-making in digital environments. He holds a B.A in International Relations and Media Studies from New York University (NYU) and an M.B. A in Marketing and Information Systems from City University of New York (CUNY) Baruch Colmation: albany.edu/ nd115232/ lege's Zicklin School of Business, both Cum Laude. For more infor-

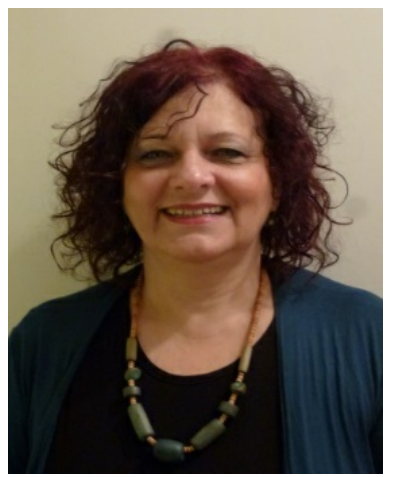

Ruti Gafni is the Head of the Information Systems B.Sc. program at The Academic College of Tel Aviv Yaffo. She holds a PhD from Bar-Ilan University, Israel (in the Business Administration School), focusing on Information Systems, an M.Sc. from Tel Aviv University and a BA (Cum Laude) in Economics and Computer Science from Bar-Ilan University. She has more than 40 years of practical experience as Project Manager and Analyst of information systems. 